\title{
Photon yields and decay times of cross luminescence in ionic crystals*
}

\author{
P. Dorenbos, R. Visser, C.W.E. van Eijk \\ Radiation Technology Group, Department of Applied Physics, \\ Delft University of Technology, Mekelweg 15, 2629 JB Delft, the Netherlands
}

J. Valbis

Institute of Solid State Physics, University of Latvia, Riga, Latvia

N.M. Khaidukov

Institute of General and Inorganic Chemistry, Moscow, USSR

\begin{abstract}
We have studied the scintillation properties of $\mathrm{KMgF}_{3}$, $\mathrm{KYF}_{4}: \mathrm{Rb}, \mathrm{K}_{2} \mathrm{YF}_{5}, \mathrm{KLuF}_{4}, \mathrm{RbMgF}_{3}, \mathrm{KZnF}_{3}, \mathrm{BaTm}_{2} \mathrm{~F}_{8}$, $\mathrm{LiYF}_{4}: \mathrm{Nd}$ and $\mathrm{BaF}_{2}: \mathrm{Rb}$. The first four crystals produce cross-luminescence (CL) with a decay time of about $1.5 \mathrm{~ns}$. $\mathrm{CL}$ was not observed for the other crystals.
\end{abstract}

\section{Introduction}

The discovery of a fast intrinsic luminescence with a decay time of $0.8 \mathrm{~ns}$ in $\mathrm{BaF}_{2}$ crystals [1] started a renewed interest in scintillation materials. This so-called crossluminescence (CL) is caused by transitions of electrons from the $\mathrm{F}^{-} 2 \mathrm{p}$-valence band to holes, created by ionizing radiation, in the $\mathrm{Ba}^{2}+5 \mathrm{p}$-core band [2]. Since the discovery of fast scintillations in $\mathrm{BaF}_{2}$, other inorganic crystals were found to exhibit $\mathrm{CL}$, e.g. the alkali halides CsF, $\mathrm{CsCl}, \mathrm{CsBr}, \mathrm{RbF}, \mathrm{RbCl}$, and $\mathrm{KF}$ and ternary compounds like $\mathrm{KMgF}_{3}, \mathrm{KCaF}_{3}, \mathrm{KLuF}_{4}, \mathrm{~K}_{2} \mathrm{YF}_{5}, \mathrm{BaLiF}_{3}, \mathrm{BaMgF}_{4}$, $\mathrm{BaY}_{2} \mathrm{~F}_{8}, \mathrm{BaZnF}_{4}, \mathrm{CsCaCl}_{3}[3,4,5,6,7,8,9]$. Extrinsic CL was reported for the cation doped alkali halides $K F: R b$, $\mathrm{KCl}: \mathrm{Cs}$, and $\mathrm{RbCl}: \mathrm{Cs}[3,10]$. In these materials, electron transitions from the halogen-related valence band to holes at impurity cations produce CL. The CL decay time is usually very short (ns) which is a highly desirable property for fast timing purposes in radiation detection systems.

In this work, we report on the scintillation properties of the ternary inorganic crystals $\mathrm{KMgF}_{3}, \mathrm{RbMgF}_{3}$, $\mathrm{KYF}_{4}: \mathrm{Rb}, \mathrm{K}_{2} \mathrm{YF}_{5}, \mathrm{KZnF}_{3}, \mathrm{BaTm}_{2} \mathrm{~F}_{8}, \mathrm{KLuF}_{4}, \mathrm{LiYF}_{4}: \mathrm{Nd}$ and $\mathrm{BaF}_{2}: \mathrm{Rb}$. The scintillation light output of these crystals was estimated from the $\mathrm{X}$-ray induced emission spectra. Optical absorption spectra and decay time spectra were also measured and are presented. The $\mathrm{Rb}^{+}$doped materials are of interest because of possible extrinsic CL

*These investigations in the program of the Foundation for Fundamental Research on Matter (FOM) have been supported by the Netherlands Technology Foundation (STW) behaviour. CL was already observed recently for $\mathrm{KMgF}_{3}$, $\mathrm{KYF}_{4}, \mathrm{~K}_{2} \mathrm{YF}_{5}$, and $\mathrm{KLuF}_{4}$ crystals $[3,11,12]$. However, little is known about the absolute CL light output and its decay time on which we report in this work. The other crystals did not show evidence for CL. The $\mathrm{Nd}^{3+}$ doped $\mathrm{LiYF}_{4}$ crystal is of interest because of a $5 \mathrm{~d}-4 \mathrm{f}$ emission from $\mathrm{Nd}^{3+}$ at $185 \mathrm{~nm}$.

\section{Experimental details}

The $\mathrm{K}_{2} \mathrm{YF}_{5}, \mathrm{KYF}_{4}: \mathrm{Rb}$ and $\mathrm{KLuF}_{4}$ single crystals were obtained by the hydrothermal synthesis method in the reaction of water solutions of KF with the corresponding oxides of rare earth elements. The synthesis was performed in a $40 \mathrm{~cm}^{3}$ autoclave with copper ampullae at $\approx 750 \mathrm{~K}$ temperature and $100-150 \mathrm{MPa}$ pressure. The other crystals were grown by the conventional Bridgman method in graphite crucibles under protective atmosphere. The crystals were not analysed for the content of trace impurities. The authors are grateful to R. Yu Abdulsabirov, S.V. Petrov, V.M. Reiterov, N.I. Silkin, and H.W. den Hartog for some of the crystals studied in this work.

An ARC (Acton Research Corporation) vacuum monochromator (model VM-502) with a 1200 grooves $/ \mathrm{mm}$ concave holographic grating blazed in first order at 250 $\mathrm{nm}$ was employed to measure the luminescence spectra of the crystals. The crystals were excited with $\mathrm{X}$-rays from an X-ray tube with a copper anode operating at $35 \mathrm{kV}$. $A$ diaphragm located between the crystal and the $\mathrm{X}$-ray tube assured a well defined $X$-ray beam on the crystal surface. Several pure $\mathrm{BaF}_{2}$ crystals with different dimensions showed within $5 \%$ the same luminescence intensity. The emission spectra recorded with our set-up is therefore rather independent on crystal dimensions.

An XP2020Q photomultiplier (PM)-tube operating in current mode was mounted behind the exit slit of the monochromator and measures the transmitted light. Since the PM-tube is insensitive at wavelengths smaller than 170 
$\mathrm{nm}$, a Na-salicylate coated glass window with an XP2020 PM-tube was used for measuring emission spectra near these wavelengths. The emission spectra presented in this work were corrected for the quantum efficiencies (QE) of the photon detectors. We employed the $Q E$ of the PMtube as specified by the manufacturer. The $Q E$ of Nasalicylate at wavelengths between 170 and $240 \mathrm{~nm}$ was determined by comparing the spectrum of a deuterium lamp recorded with Na-salicylate with the one recorded with the PM-tube; below $170 \mathrm{~nm}$ a constant extrapolated value was assumed. An estimate for the relative photon yield was obtained by comparing these corrected emission spectra with the one of a pure $\mathrm{BaF}_{2}$ crystal recorded under identical conditions. Our pure $\mathrm{BaF}_{2}$ reference crystal, if excited with $662 \mathrm{keV}$ gamma rays, has a total light yield of 10000 photons per $\mathrm{MeV}$ absorbed gamma ray energy of which $1800 \mathrm{ph} / \mathrm{MeV}$ are created by core-valence transitions. With these values and the assumption that the light yield/(unit energy) for about $10 \mathrm{keV}$ X-rays is the same as for $662 \mathrm{keV}$ gamma rays, an absolute estimate for the photon yield was obtained. The, in this work reported, photon yields of emissions observed at wavelengths below $200 \mathrm{~nm}$ can have a systematic error of possibly $30 \%$ because the quantum efficiency of Na-Salicylate and the XP2020Q PM-tube are not accurately known below 200 $\mathrm{nm}$. Furthermore, the results were not corrected for the transmission of the monochromator. In addition, there is a stochastic error of about $15 \%$ in the reported photon yields.

The optical absorption of the crystals between 200 and $600 \mathrm{~nm}$ was measured by means of a Perkin-Elmer spectrophotometer (model lambda 9). An ARC (model DS775) deuterium lamp was used to determine the optical absorption of the crystals at wavelengths between 110 and $240 \mathrm{~nm}$. Decay time spectra of the scintillation emission from the crystals were determined by means of single photon counting techniques. We employed a modified version of the method described by Bollinger et al. [13]. The decay time spectra were corrected for dead time and counts caused by random coincidences.

\section{Results}

A. $K M g F_{3}$. CL in $\mathrm{KMgF}_{3}$ between 140 and $190 \mathrm{~nm}$ was reported some years ago by Jansons et al. [3]. Buzulutskov et al. [11] reported an intensity about $43 \%$ of that of pure $\mathrm{BaF}_{2}$. We studied two cylindrical $\mathrm{KMgF}_{3}$ crystals with dimensions $\emptyset 6.7 \times 3.1 \mathrm{~mm}$ and $\emptyset 6.5 \times 1.6 \mathrm{~mm}$ containing traces of $\mathrm{Eu}^{2+}$. The emission, optical transmission, and decay time spectra of the $3 \mathrm{~mm}$ thick crystal are shown in figures 1, 2 and 3 respectively. The CL can be observed between 140 and $190 \mathrm{~nm}$ and has a decay time of $1.5 \pm 0.3$ ns. The transmission of the crystal at 140 and $190 \mathrm{~nm}$ is $15 \%$ and $59 \%$, respectively. From the integrated emission spectrum, we obtain a CL light yield of about 2400 photons $/ \mathrm{MeV}$. The $1.6 \mathrm{~mm}$ thick crystal had a CL light yield of $3500 \mathrm{ph} / \mathrm{MeV}$. This larger value is caused by a better optical transmission of the crystal near $170 \mathrm{~nm}$.

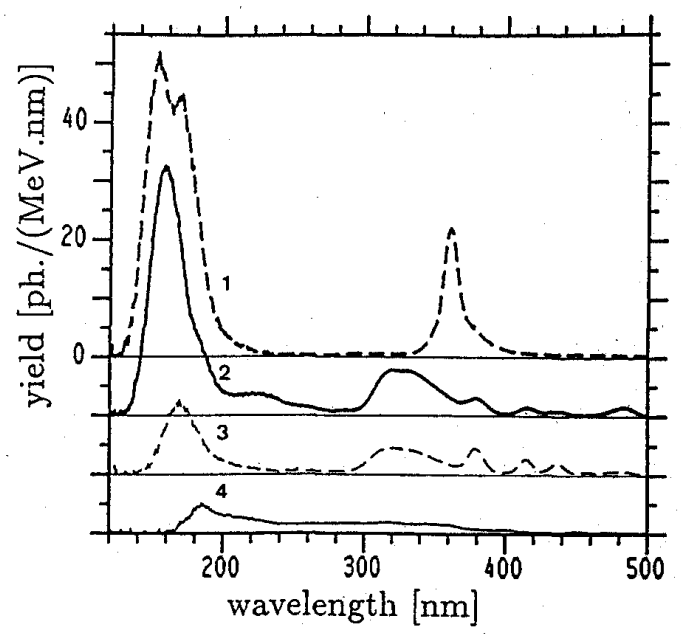

Figure 1: $\mathrm{X}$-ray induced emission spectra at room temperature. Spectrum 1) $3.1 \mathrm{~mm}$ thick $\mathrm{KMgF}_{3}$; 2) $\mathrm{KYF}_{4}: \mathrm{Rb}^{3}$ ) $\mathrm{K}_{2} \mathrm{YF}_{5}$;4) $\mathrm{KLuF}_{4}$. For illustration purposes, the last three spectra are shifted vertically by multiples of $-10 \mathrm{ph} /(\mathrm{MeV} \cdot \mathrm{nm})$.

Optical absorptions between 220 and $300 \mathrm{~nm}$, partly visible in Fig. 2, are caused by $4 \mathrm{f}-5 \mathrm{~d}$ transitions in $\mathrm{Eu}^{2+}$. The emission peak at $363 \mathrm{~nm}$ with a light yield of 675 photons $/ \mathrm{MeV}$ must be attributed to a $4 \mathrm{f}-4 \mathrm{f}\left({ }^{6} \mathrm{P}_{-}{ }^{8} \mathrm{~S}\right)$ transition in $\mathrm{Eu}^{2+}[14]$. Since the $4 \mathrm{f}-4 \mathrm{f}$ emission is forbidden according to the electric dipole approximation, its decay time is very long (about $1 \mathrm{~ms}$ [14]) and therefore of no practical interest for scintillation techniques.

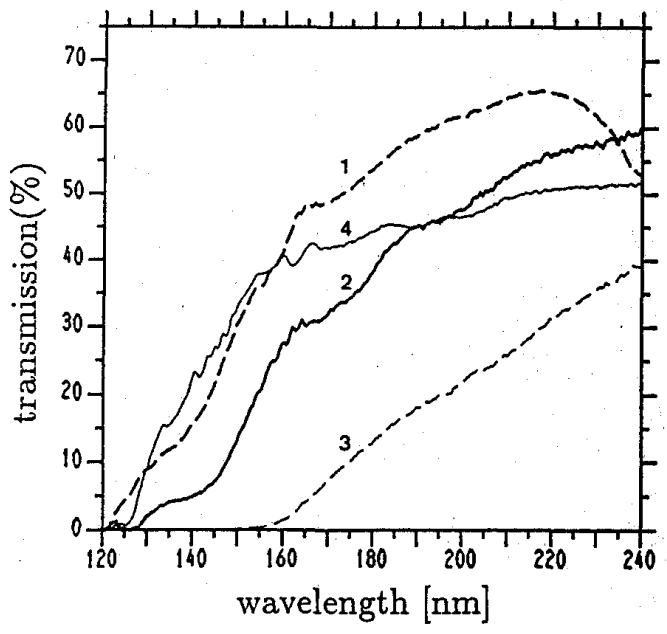

Figure 2: Optical transmission spectra not corrected for Fresnel reflections of 1) $3.1 \mathrm{~mm}$ thick $\mathrm{KMgF}_{3}$; 2) $\mathrm{KYF}_{4}: \mathrm{Rb}$; 3) $\mathrm{K}_{2} \mathrm{YF}_{5}$; 4) $\mathrm{KLuF}_{4}$.

B. $K_{2} Y F_{5}$ and $K Y F_{4}: R b$. The emission, optical absorp- 
tion, and decay time spectra of these crystals with dimensions $6 \times 8 \times 3.1 \mathrm{~mm}$ and $5 \times 5 \times 0.75 \mathrm{~mm}$, respectively, are also shown in figures 1,2 , and 3 . CL in $\mathrm{K}_{2} \mathrm{YF}_{5}$ with an intensity about $17 \%$ of that of pure $\mathrm{BaF}_{2}$ was reported by Buzulutskov et al. [11]. We observe CL in the $140-220 \mathrm{~nm}$ region with a light yield of $510 \mathrm{ph} / \mathrm{MeV}$ and with a decay time of $1.3 \pm 0.3 \mathrm{~ns}$. A significant fraction of the CL is probably absorbed in the crystal because of the rather poor optical transmission of $7.5 \%$ near $170 \mathrm{~nm}$. The emission band at $320 \mathrm{~nm}$ might be caused by $5 \mathrm{~d}-4 \mathrm{f}$ luminescence of $\mathrm{Ce}^{3+}$ impurities. There is slight evidence of a decay time component of about 20 ns and two optical absorption bands at 205 and $288 \mathrm{~nm}$ which correspond with $4 \mathrm{f}-5 \mathrm{~d}$ transitions in $\mathrm{Ce}^{3+}$. The narrower peaks near $378 \mathrm{~nm}, 415 \mathrm{~nm}$, and $435 \mathrm{~nm}$ are possibly caused by $4 \mathrm{f}-4 \mathrm{f}$ luminescence of $\mathrm{Nd}^{3+}$ impurities.

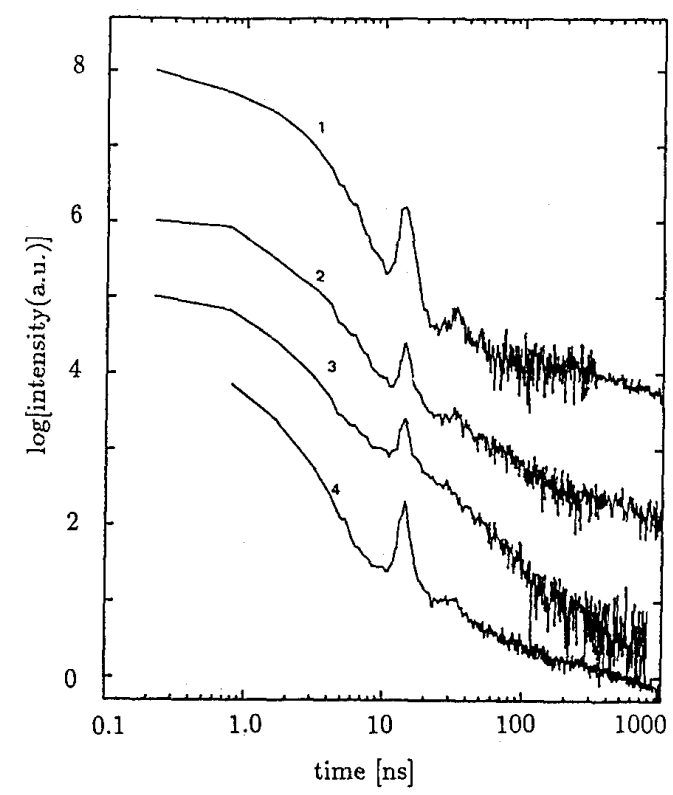

Figure 3: Decay time spectra at room temperature and plotted on a ${ }^{10} \log _{-}{ }^{10} \log$ scale. 1) $3.1 \mathrm{~mm}$ thick $\mathrm{KMgF}_{3}$; 2) $\mathrm{KYF}_{4}: \mathrm{Rb}$; 3) $\mathrm{K}_{2} \mathrm{YF}_{5}$;4) $\mathrm{KLuF}_{4}$. The small peaks at 15 and $30 \mathrm{~ns}$ are artifacts caused by after pulses in a photomultiplier tube.

The $\mathrm{KYF}_{4}$ crystal was doped with $\mathrm{Rb}^{+}$in order to obtain extrinsic CL. Initially holes are created by ionizing radiation in the $K^{+} 3 p$-shell, and it was anticipated that they would be trapped by $\mathrm{Rb}^{+}$ions. A transition of an electron from the $F^{-} 2 p$-valence band to the relaxed hole would then produce extrinsic CL near $225 \mathrm{~nm}$ similar as it was observed in KF:Rb crystals [3]. The $\mathrm{KYF}_{4}: \mathrm{Rb}$ crystal shows CL in the $140-190 \mathrm{~nm}$ region with a yield of 1800 $\mathrm{ph} / \mathrm{MeV}$, i.e. equal to that of pure $\mathrm{BaF}_{2}$, and has an optical transmission of $28 \%$ at $160 \mathrm{~nm}$. The larger CL light yield as compared to $\mathrm{K}_{2} \mathrm{YF}_{4}$ is probably caused by the better optical transmission of the crystal. The emission lines in the 300 to $500 \mathrm{~nm}$ region, with a total light yield of 840 $\mathrm{ph} / \mathrm{MeV}$, are very similar to those of the $\mathrm{K}_{2} \mathrm{YF}_{5}$ crystal.
A faint emission band can be observed near $225 \mathrm{~nm}$ where the extrinsic CL was anticipated. Whether this is caused by extrinsic CL due to $\mathrm{Rb}$ or some other defect is not clear.

C. $K L u F_{4}$. Buzulutskovet al. [8] reported that $\mathrm{KLuF}_{4}$ crystals show, like $\mathrm{KMgF}_{3}, \mathrm{CL}$ between 140 and $200 \mathrm{~nm}$. We studied a crystal with dimensions $6 \times 8 \times 1.2 \mathrm{~mm}$, its spectra are again shown in Figures 1, 2 and 3. Contrary to Buzulutskovet al. [8], we did not observe CL below 170 $\mathrm{nm}$. There is, however, a fast component of $1.3 \pm 0.3$ ns in the decay time spectrum, possibly caused by CL between 170 and $200 \mathrm{~nm}$ with a yield of about $170 \mathrm{ph} / \mathrm{MeV}$. The absence of CL below $170 \mathrm{~nm}$ can not be explained by optical self absorption in the crystal because the optical transmission at these wavelengths is reasonably good, see Figure 2. The origin of the faint broad emission band extending from 200 to $500 \mathrm{~nm}$ is not known. Its total light yield is about $540 \mathrm{ph} / \mathrm{MeV}$.

D. $K Z n F_{3}, B a T m_{2} F_{8}$ and $R b M g F_{3}$. These crystals did not show any evidence of $C L$. The $K \mathrm{KnF}_{3}$ crystal has an emission band at $260 \mathrm{~nm}$ with a yield of about 2300 photons/ $\mathrm{MeV}$ and a decay time larger than 5 microseconds. This emission is probably caused by $\mathrm{Pb}^{2+}$ contamination of the crystal. Optical absorption bands at 191, 176, and $155 \mathrm{~nm}$ also indicate the presence of $\mathrm{Pb}$. The absence of $\mathrm{CL}$ is most likely caused by the overlapping of the $\mathrm{Zn}^{2+}$ $3 \mathrm{~d}$-core band with the $\mathrm{F}^{-} 2 \mathrm{p}$-valence band. The authors are grateful to Dr. Yu. P. Kostikov for the measurements of XPS (X-ray photon spectroscopy) spectra on this crystal which revealed the overlap of the energy bands. The $\mathrm{BaTm}_{2} \mathrm{~F}_{8}$ crystal showed between $180 \mathrm{~nm}$ and $600 \mathrm{~nm}$ optical absorption peaks and emission lines characteristic for the $4 \mathrm{f}-4 \mathrm{f}$ transitions in $\mathrm{Tm}^{3+}$ ions. The emissions were very weak with light yields smaller than 20 photons/MeV. Fast emissions, characteristic for CL were not observed, most likely because of the partly filled $4 f$ shell of $\mathrm{Tm}^{3+}$. For the same reason $\mathrm{KErF}_{4}, \mathrm{KTmF}_{4}$, and $\mathrm{KYbF}_{4}$ do not emit a CL component $[12,8]$. The emission spectrum of $\mathrm{RbMgF}_{3}$ showed a weak ( 400 photons $/ \mathrm{MeV}$ ) broad emission band with some structure between $200 \mathrm{~nm}$ and 450 $\mathrm{nm}$. An emission line with a width of about $60 \mathrm{~nm}$ and a total intensity of 1800 photons/MeV was observed near $575 \mathrm{~nm}$. Their decay times were not measurable with our set-up and must be longer than $0.1 \mathrm{~ms}$. This material is because of this long decay time not a practical scintillator. The absence of an expected measurable $\mathrm{CL}$ in $\mathrm{RbMgF}_{3}$ can be caused by a too high concentration of $\mathrm{Pb}$ and other impurities.

E. $B a F_{2}: R b$. Crystals of $\mathrm{BaF}_{2}$ doped with $\mathrm{Rb}$ were studied because of a possible extrinsic CL. However, we did not observe any luminescence related to $\mathrm{Rb}^{+}$, and the anticipated extrinsic CL was therefore not observed. The only effect of $\mathrm{Rb}^{+}$doping was a reduction of the intensity of the STE emission of the host lattice.

F. $L i Y F_{4}: N d^{3+}$. The emission spectrum of a $7 \mathrm{~mm}$ thick $\mathrm{LiYF}_{4}$ crystal doped with $0.9 \mathrm{~mol} \% \mathrm{Nd}$ is shown in figure 4a. The properties appear quite similar to those of $\mathrm{Nd}^{3+}$ doped $\mathrm{LaF}_{3}$ crystals [15]. For comparison, the emission 
spectrum of a $\mathrm{LaF}_{3}$ crystal doped with $1.2 \mathrm{~mol} \% \mathrm{Nd}^{3+}$ is show in figure $4 \mathrm{~b}$. The emission lines between 340 and 500 $\mathrm{nm}$, with a total light yield of 250 and 1600 photons/MeV for $\mathrm{LiYF}_{4}: \mathrm{Nd}$ and $\mathrm{LaF}_{3}: \mathrm{Nd}$, respectively, are caused by 4f- $4 \mathrm{f}$ transitions in $\mathrm{Nd}^{3+}$ ions. The $4 \mathrm{f}-4 \mathrm{f}$ luminescence decay times are usually very long (ms) and therefore not suitable for scintillation techniques. The emission lines at 182,230 , and $260 \mathrm{~nm}$ for $\mathrm{LiYF}_{4}: \mathrm{Nd}$ are caused by $5 \mathrm{~d}-4 \mathrm{f}$ emissions. The optical absorption edge caused by $4 \mathrm{f}-5 \mathrm{~d}$ absorption is located at $180 \mathrm{~nm}$. The position of the $5 \mathrm{~d}-4 \mathrm{f}$ emission differs somewhat from those in $\mathrm{Nd}^{3+}$ doped $\mathrm{LaF}_{3}$ crystal because of a different interaction between the $5 \mathrm{~d}$ shell of $\mathrm{Nd}^{3+}$ with the host lattice. The $184 \mathrm{~nm}$ emission in $\mathrm{LiYF}_{4}: \mathrm{Nd}$ and the $173 \mathrm{~nm}$ emission in $\mathrm{LaF}_{3} ; \mathrm{Nd}$, both about 200 photons $/ \mathrm{MeV}$, are of interest because of detection with photosensitive gasses. The decay time was expected to be short since the $5 \mathrm{~d}-4 \mathrm{f}$ transition is an allowed transition. We observed a decay time of about 40 ns for $\mathrm{LiYF}_{4}: \mathrm{Nd}$ and $6.3 \mathrm{~ns}$ for $\mathrm{LaF}_{3}: \mathrm{Nd}[15]$.

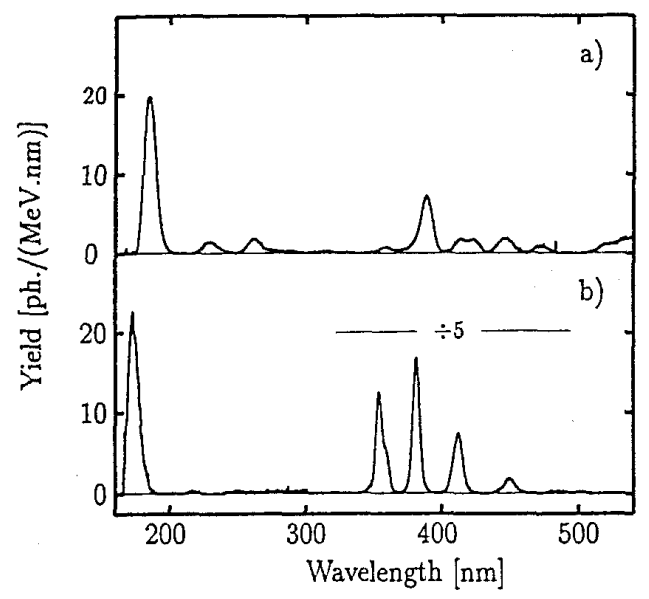

Figure 4: X-ray induced emission spectra. a) $\mathrm{LiYF}_{4} ; 0.9 \mathrm{~mol} \%$ $\mathrm{Nd}^{3+}$. b) $\mathrm{LaF}_{3}: 1.2 \mathrm{~mol} \% \mathrm{Nd}^{3+}$; the intensity above $300 \mathrm{~nm}$ is divided by 5 for illustration purposes.

\section{Discussion}

Table 1 compiles the CL data obtained in this work. In order to interpret the photon yield/MeV one should consider the optical transmission of the crystals. The exciting $\mathrm{X}$-rays are absorbed in the top layer of these crystals, and the created CL-photons have to transmit through the bulk material in order to be detected. Part of the photons will then be absorbed. If one corrects the photon yields for this self absorption, we obtain for $\mathrm{KYF}_{4}, \mathrm{~K}_{2} \mathrm{YF}_{5}$, and both crystals of $\mathrm{KMgF}_{3}$ a photon yield/MeV of roughly 5000 at a bulk transmission of $100 \%$. In the correction, we have assumed a linear dependence of the light yield on the transmittance. It seems therefore that these crystals,
Table 1: Compilation of cross-luminescence data obtained in this work. $d=$ crystal thickness; $\lambda=C L$-emission wavelength; $\mathrm{ph} / \mathrm{MeV}=$ photon yield per $\mathrm{MeV}$ absorbed $\mathrm{X}$-ray energy with a possible (except for $\mathrm{BaF}_{2}$ ) systematic error of $30 \% ; \tau=\mathrm{CL}$ decay time.

\begin{tabular}{|l|l|c|c|c|}
\hline crystal & $\mathrm{d}(\mathrm{mm})$ & $\lambda(\mathrm{nm})$ & $\mathrm{ph} / \mathrm{MeV}$ & $\tau(\mathrm{ns})$ \\
\hline & & & & \\
$\mathrm{BaF}_{2}$ & 5 & 195,220 & $1800 \pm 100$ & $0.8 \pm 0.1$ \\
$\mathrm{KMgF}_{3}$ & 3.1 & $140-190$ & $2500 \pm 400$ & $1.5 \pm 0.3$ \\
$\mathrm{KMgF}_{3}$ & 1.6 & $140-190$ & $3500 \pm 500$ & - \\
$\mathrm{KYF}_{4}$ & 0.75 & 170 & $1800 \pm 300$ & $1.9 \pm 0.4$ \\
$\mathrm{~K}_{2} \mathrm{YF}_{5}$ & 3.1 & 170 & $510 \pm 80$ & $1.3 \pm 0.3$ \\
$\mathrm{KLuF}_{4}$ & 1.2 & $170-200$ & $170 \pm 40$ & $1.3 \pm 0.3$ \\
\hline
\end{tabular}

if optically pure, have about equal CL-light yields which are about twice as large as that of pure $\mathrm{BaF}_{2}$.

Except for $\mathrm{BaF}_{2}$ and $\mathrm{CsF}$, little is known in the literature about the absolute CL light output. In many cases the intensity is reported relative to the intensity of some other crystal showing CL without a correction for the quantum efficiencies and transmissions of the photon detection systems. Sometimes, e.g. for $\mathrm{KF}$ and $\mathrm{RbCl}$, only an order of magnitude is given. Furthermore, little is known about the optical quality of the crystals and the light collection efficiency. Nevertheless, we have tried to obtain an estimate for the photon yield/MeV of most CL-crystals reported in the literature up to date and compiled them in Table 2 .

Principally, the CL light yield/MeV is determined by the number of holes/ $\mathrm{MeV}$ created in the core band and the competition between radiative and non-radiative decay of the holes. The low light yield of $\mathrm{KF}, \mathrm{RbCl}$, and $\mathrm{CsBr}$ at room temperature and the extremely short decay time of 70 ps reported for $\mathrm{CsBr}$ [5], for instance, are caused by competing Auger decay of the holes $[5,6]$. The crystals $\mathrm{RbF}, \mathrm{KMgF}_{3}, \mathrm{KCaF}_{3}, \mathrm{CsBr}$ at $80 \mathrm{~K}$, and probably $\mathrm{CsCl}$ at $80 \mathrm{~K}$, have light yields comparable with those of $\mathrm{BaF}_{2}$ and CsF. The CL photon yields reported by Buzulutskovet al. $[11,8]$ of the potassium compounds $\mathrm{KMgF}_{3}$ and $\mathrm{K}_{2} \mathrm{YF}_{5}$ are significantly smaller than observed by us; compare Table 1 with 2 . It is not known to what extend these yields are affected by the optical properties and the shape of the crystals. Melchakovet al. and Rodnyi et al. . $[7,9,17]$ report for $\mathrm{CsCaCl}_{3}, \mathrm{CsSrCl}_{3}, \mathrm{RbCaF}_{3}, \mathrm{BaLiF}_{3}, \mathrm{BaMgF}_{4}$, $\mathrm{BaZnF}_{4}$, and $\mathrm{BaY}_{2} \mathrm{~F}_{8} \mathrm{CL}$ photon yields comparable with that of pure $\mathrm{BaF}_{2}$ and decay times of the order of $1 \mathrm{~ns}$. It appears from the results in Table 2 that, generally, the extra metal ion in the ternary compounds causes a small shift of the CL emission band to larger wavelengths. In addition, the Auger decay which sometimes dominates the radiative decay at room temperature is often of less importance in the ternary compounds. E.g. CL in KF is quenched at room temperature whereas Auger quenching is not observed for the ternary potassium compounds; the 
Table 2: Compilation of $\mathrm{CL}$ data at room temperature reported in the literature. $\lambda=\mathrm{CL}$-emission wavelength; $\mathrm{ph} / \mathrm{MeV}$ = estimated photon yield per $\mathrm{MeV}$ absorbed energy. This number is in many cases a rough estimate and must be interpreted accordingly; $\tau=$ CL decay time.

\begin{tabular}{|l|l|l|l|c|}
\hline crystal & $\lambda(\mathrm{nm})$ & $\mathrm{ph} / \mathrm{MeV}$ & $\tau(\mathrm{ns})$ & ref. \\
& & & & \\
\hline $\mathrm{KF}^{a)}$ & 156 & $50-200$ & - & {$[3]$} \\
$\mathrm{RbF}$ & 203,234 & 1700 & $1.3 \pm 0.1$ & {$[4,5]$} \\
$\mathrm{CsF}$ & 390 & 2500 & $2.9 \pm 0.1$ & {$[5,16]$} \\
$\mathrm{RbCl}$ & 190 & $0.5-2$ & - & {$[3]$} \\
$\mathrm{CsCl}{ }^{b)}$ & 245,270 & 900 & $0.88 \pm 0.07$ & {$[5]$} \\
$\mathrm{CsCl}$ & 236,276 & - & $1.5 \pm 0.5$ & {$[7]$} \\
$\mathrm{CsBr}$ & 250 & 18 & 0.07 & {$[5]$} \\
$\mathrm{CsBr}$ & 250 & 1800 & $1.34 \pm 0.05$ & {$[5]$} \\
$\mathrm{KCaF}_{3}$ & 155,171 & 1800 & $<2$ & {$[3]$} \\
$\mathrm{KMgF}_{3}$ & 152,171 & $800 \pm 250$ & $<2$ & {$[11,8]$} \\
$\mathrm{K}_{2} \mathrm{YF}_{5}$ & 180 & $200 \pm 60$ & $1.3 \pm 0.3$ & {$[8]$} \\
$\mathrm{KLuF}_{4}$ & 165 & $400 \pm 120$ & $<2$ & {$[8]$} \\
$\mathrm{KLu}_{2} \mathrm{~F}_{7}$ & 165 & 270 & $<2$ & {$[11]$} \\
$\mathrm{RbCaF}_{3}$ & - & 1800 & $\approx 1$ & {$[17]$} \\
$\mathrm{KCaCl}_{3}{ }^{c)}$ & - & 1800 & $\approx 1$ & {$[17]$} \\
$\mathrm{CsCaCl}_{3}$ & 248,305 & 1800 & $<1.0$ & {$[7,17]$} \\
$\mathrm{CsSrCl}_{3}$ & - & 1800 & $\approx 1$ & {$[17]$} \\
$\mathrm{BaF}_{2}$ & 195,220 & 1800 & $0.8 \pm 0.1$ & {$[1]$} \\
$\mathrm{BaLiF}_{3}{ }^{d)}$ & 228,252 & 1800 & $<1.0$ & {$[9]$} \\
\hline
\end{tabular}

a) at $80 \mathrm{~K}$, the emission is almost entirely quenched at room temperature due to Auger processes [3]. $\left.{ }^{b}\right)$ The light yield of $\mathrm{CsCl}$ increases by a factor of two upon cooling the crystal to $80 \mathrm{~K} \mathrm{[7].}{ }^{c)}$ at $80 \mathrm{~K} \cdot{ }^{d)} \mathrm{BaMgF}_{4}, \mathrm{BaY}_{2} \mathrm{~F}_{8}$, and $\mathrm{BaZnF}_{4}$ show, in this order, increasingly lower $\mathrm{Cl}$ intensity than $\mathrm{BaLiF}_{3}[9]$.

same holds for $\mathrm{KCl}$ and $\mathrm{CsCl}$ and the related ternary compounds. These properties are probably caused by a widening of the bandgap between the conduction band and the upper valence band due to the presence of the extra metal ions.

Summarizing, the CL decay time of crystals known sofar is usually between 1 and 2 ns, and there appears little variation with crystal type. $\mathrm{BaF}_{2}$ is still the fastest scintillator with a decay time of $0.8 \pm 0.1$ ns. It seems that the CL photon yield of all crystals showing CL is of the same order of magnitude; a few thousand photons $/ \mathrm{MeV}$. Accurate numbers for the photon light yield are for most crystals not yet known.

\section{References}

[1] M. Laval, M. Moszynski, R. Allemand, E. Cormoreche, P. Guinet, R. Odru, J. Vacher, "Barium fluoride - inorganic scintillator for subnanosecond timing", Nucl. Instr. and Meth., vol. 206, pp. 169, 1983.

[2] Yu. M. Aleksandrov, V.N. Makhov, P.A. Rodnyi, T.I.
Syreishchikova, M.N. Yakimenko, "Intrinsic luminescence of $\mathrm{BaF}_{2}$ excited by synchrotron radiation pulses", Sov. Phys. Solid State, vol. 26, pp. 1734, 1984.

[3] J.L. Jansons, V.J. Krumins, Z.A. Rachko, J.A. Valbis, "Crossluminescence of $\mathrm{KF}$ and related compounds", Solid State Comm., vol. 67, pp. 183, 1988.

[4] A.B. Golovin, P.A. Rodnyi, M.A. Terekhin, "Intrinsic luminescence of $\mathrm{CsF}$ and $\mathrm{RbF}$ at high energy excitation", Pis'ma Zh. Tverd. Fiz., vol. 15(8), pp. 29, 1989.

[5] S. Kubota, J. Ruan(Gen), M. Itoh, S. Hashimoto, S. Sakuragi, "A new type of luminescence mechanism in large band-gap insulators: proposal for fast scintillation materials", Nucl. Instr. and Meth., vol. A289, pp. 253, 1990.

[6] J.L. Jansons, V.J. Krumins, Z.A. Rachko, J.A. Valbis, "Luminescence due to radiative transitions between valence band and upper core band in ionic crystals (crossluminescence)", Phys. Stat. Sol. (b), vol.144, pp. 835, 1987.

[7] E.N. Mel'chakov, P.A. Rodnyi, B.V. Rybakov, A.J. Smakov, M.A. Terekhin, "Luminescence by core-valence transitions in $\mathrm{CsCl}$ and $\mathrm{CsCaCl}_{3}$ crystals", Fiz. Tverd. Tela, vol. 31(5), pp. 276, 1989.

[8] A.F. Buzulutskov, L.K. Turchanovich, V.G. Vasilchenko, J.L. Jansons, Z.A. Rachko, J.A. Valbis, N.M. Khaidukov, "Investigation of the crystal scintillations in the VUV region", Nucl. Instr. and Meth., vol. A288, pp. 659, 1990.

[9] P.A. Rodnyi, M.A. Terekhin, E.N. Mel'chakov, "Radiative core-valence transitions in barium-based fluorides", $J$. of Luminescence, vol 47, pp. 281, 1991.

[10] I. Kuusmann, T. Kloiber, W. Laasch, G. Zimmerer, "Intrinsic and extrinsic crossluminescence in ionic crystals", presented at the sixth European LATDIM Conference, Groningen, The Netherlands, 3-7 sept 1990.

[11] A.F. Buzulutskov, L.K. Turchanovich, V.G. Vasil'chenko, "Coupling of a $\mathrm{KMgF}_{3}$ scintillator to a wire chamber filled with triethylamine", Nuclear Instr. and Meth., vol. A281, pp. 99, 1989.

[12] V.N. Makhov and N.M. Khaidukov, "Characteristics of cross luminescence in $\mathrm{KYF}_{4}$ and $\mathrm{KLuF}_{4}$ crystals". Sov. Phys. Solid. State, vol 32(11), pp. 1978, 1990.

[13] L.M. Bollinger, G.E. Thomas, "Measurements of the time dependence of scintillation intensity by a delayedcoincidence method", Rev. Sci. Instr., vol. 32, pp. 1044, 1961.

[14] N.S. Al'tshuler, E.Kh. Ivoilova, A.L. Stolov, "Cubic Eu ${ }^{2+}$ centers in perovskite-type crystals", Sov. Phys. Solid. State, vol. 15 pp. 1602, 1974.

[15] P. Dorenbos, C.W.E. van Eijk, R.W. Hollander, P. Schotanus, "Scintillation properties of $\mathrm{Nd}^{3+}$ doped $\mathrm{LaF}_{3}$ crystals", IEEE Trans. Nucl. Sci., vol. 37(2), pp. 119, 1990.

[16] M. Moszynski, C. Gresset, J. Vacher, R. Odru, "Properties of $\mathrm{CsF}$, a fast inorganic scintillator in energy and time spectroscopy", Nucl. Instr. and Meth., vol 179 pp. 271, 1981.

[17] E.N. Melchakhov and P.A. Rodnyi, "Roentgenoluminescence properties of crystals with core-valence transitions", presented at the LUMDETR'91 symposium, October 9-12 Riga, Latvia, 1991. 